\title{
ERUCA SATIVA LINN.: PHARMACOGNOSTICAL AND PHARMACOLOGICAL PROPERTIES AND PHARMACEUTICAL PREPARATIONS
}

\author{
NOOR S JAAFAR ${ }^{1}$, IMAN S JAAFAR ${ }^{2 *}$ \\ ${ }^{1}$ Department of Pharmacognosy and Medicinal Plants, College of Pharmacy, University of Baghdad, Baghdad, Iraq. ${ }^{2}$ Department of \\ Pharmaceutics, College of Pharmacy, University of Almustansiriyah, Baghdad, Iraq. Email: pharm.eman.aldahan@uomustansiriyah.edu.iq
}

Received: 22 November 2018, Revised and Accepted: 22 December 2018

\section{ABSTRACT}

Eruca sativa (jarjeer) is an annual herb (family Brassicaceae), which contains a wide range of chemicals and minerals with nutraceutical and organoleptic characteristics. Jarjeer was generally used as a food and traditionally mainly consumed due to its aphrodisiac properties. This crop known to contain various phytochemicals such as flavonoids, phenolic acids, terpens, carotenoids, tannins, glycosides, saponins, sterols, alkaloids, and other secondary metabolites. In leaves, kaempferol and its derivatives, glucosativin, are the main flavonoids and glucosinolate, respectively, while erucic acid and glucoerucin are the main fatty acid and glucosinolate, respectively. Medicinally, the plant has antibacterial, antidiabetic, antihypertensive, antiplatelet, and antioxidant activity and stimulates hair growth and other effects. Trails on topical pharmaceutical preparations involve the use of E. sativa which had been done. These preparations include creams and waxs which are intended to be used for potentiating hair growth and skin fungal and bacterial infection.

Keywords: Eruca sativa, Jarjeer, Erucin, Aphrodisiac, Pharmaceutical preparation, Cream, Wax.

(C) 2019 The Authors. Published by Innovare Academic Sciences Pvt Ltd. This is an open access article under the CC BY license (http://creativecommons. org/licenses/by/4. 0/) DOI: http://dx.doi.org/10.22159/ajpcr.2019.v12i3.30893

\section{INTRODUCTION}

Eruca sativa is commonly known as rocket plant. The local Iraqi and Jordanian name is jarjeer [1,2]. Rocket is a member of mustard (Brassicaceae) family $[3,4]$, originated in the Mediterranean region coast, also grown in the Middle-East, South Asia, and all over the world $[5,6]$. The airy tender fresh parts of plant was used in salad and occasionally cooked as a potherb $[7,8]$, also as spice, and as a medicinal remedy for various diseases [9]. Conventionally, the plant consumed as tonic, rubefacient, astringent, digestive, laxative, emollient, stimulant, stomachic, scurvy, to increase sexual desire (aphrodisiac) [10,11] and diuretic $[10,12]$. Jarjeer seeds known to have high oil, protein, and glucosinolate content [13]. Taramira oil, the traditional spice, is produced from seeds [5]; erucic acid (long chain fatty acid) is the major constituent of taramira oil. Other constituents of taramira oil are oleic acid, linoleic acid, and saturated fatty acids. Taramira oil is used to sooth the skin, massage, soap production, and cooking, for salad, and as an adulterant for mustard oil to impart spicy taste to the latter. The taramira cake (by-product of oil production) is consumed as animal food. Livestock fed on taramira cake are seems to be ticks free [6,13-15]. Different phytochemicals have been identified in rocket including its seeds, among these flavonoids, phenolics, glucosinolate, Vitamin C, carotenoids, and others [2,11,16-18]. These compounds are responsible for the pharmacological activities of rocket such as antioxidant, cytoprotective, anticancer, antiulcer, diuretic, hepatoprotective, and other activities $[11,19,20]$.

\section{BOTONICAL DESCRIPTION}

\section{Taxonomy}

Kingdom: Plantae

Subkingdom: Tracheobionta

Superdivision: Spermatophyta

Division: Magnoliophyta

Class: Magnoliopsida

Subclass: Rosidae

Order: Brassilcales

Family: Brassicaceae

Genus: Eruca
Species: Eruca sativa

Botanical name: Eruca sativa Mill [21].

\section{Vernacular names}

Common names are jarjeer, salad, arugula, cultivated rocket, rocket salad, rugula or taramira, and white pepper [1,22-24].

\section{Morphological features}

E. sativa is an annual herbaceous leafy oilseed plant which is rising up to $80 \mathrm{~cm}$ height $[4,9,15]$ and considered as fast, cold season growing crop although it tolerates warm weather. It usually plants in Spring or Autumn in open or protected fields (greenhouses) and grow in hydroponics. Rocket also naturally scattered as weed in roadsides, waste places, corn and flax fields. This herb sustains salinity and low rainfall or drought situation. The tender leaves and shoots harvested 20-30 days after germination and then consecutively cultivated from regrowth $[4,6,25,26]$. E. sativa has a gaunt taproot, erect, rigid, and little branching hairy stem. Leaves have dull or faint green color, deeply cut, compound lobular shaped, rather fleshy, hairy, 5-15 cm long, "The basal leaves are petiolate (have a stem), and pinnately lobed or divided. They are somewhat pointed, lanceshaped, and deeply indented near the plant base. Leaves found along the stem are smaller" and have distinctive pungent or spicy flavor. Flowers are bisexual, white in color with purple veins, few in number, large in size, 2-4 cm in diameter, and borne on small terminal racemes. Flowers have erect sepals and the petals taper to a lean claw.

Fruits are cylindrical siliquae in shape with a flattened beak 3-4 mm long. Seeds are spherical or ovoid extended from 1.5 to $2 \mathrm{~mm}$, pale brown to olive green shade, and set in to 2 or 3 rows on each side [6,27-29].

\section{PHYTOCHEMISTRY}

Abroad range of phytochemicals had been identified in E. sativa leaves and seeds such as fatty acids, terpenoids, phenolics, carbohydrate, alkaloid, glycosides, saponins, sterols, and others $[9,17,18,30,31]$.

Gas chromatography-mass spectrometry (GC-MS) analysis of petroleum ether seed extract revealed the presence of seven fatty 
acids. These include myristic acid, palmitic acid, stearic acid, linoleic acid, linolenic acid, erucic acid, and oleic acid [9,32-34]. In addition to previously mentioned compound, cosaenoic acid ${\mathrm{C} 2 \mathrm{O}_{(1)}}_{\text {and nervonic }}$ acid C24 ${ }_{(1)}$ acid and nervonic acid had been identified by gas-liquid chromatography (GLC) in Egyptian seed extract [35].

Meanwhile, the fatty acid detected by GC-MS analysis of saponifiable fraction of hexane leaf extract demonstrates the presence of different fatty acids, and the main acids that present in higher percentage are palmitic acid, azelaic acid, trance-vaccenic acid (C18H3402), and palmitoleic acid [36]. That linolenic acid constitutes $48 \%$ of the fatty acid composition of rocket [32,37].

Cholesterol, secocholest-1(10)-en-3, 5-dione, $\beta$-sitosterol, and stigmasterol were detected by GC-MS analysis of unsaponifiable fraction of hexane leaf extract [36]. Campesterol and brassicasterol were also detected in E. sativa [38-40].

In seeds, $\beta$-sitosterol, cholesterol, stigmasterol, and campesterol were detected in unsaponifiable fraction of extract by GC-MS [35].

Volatile constituents such as myristicin, terpineol, apiole, cis-verbenol, and $\beta$ - phellandrene are detected in seeds [38,39], while eugenol, transanethole, elemene, (E)-b-damascone were specified in leaves $[41,42]$. Terpens as phytol, isophytol and squalene are identified in leaves $[36,41]$.

Lutein (xanthophyll), $\alpha$-tocopherol carotenoids, $\beta$-carotene (with provitamin activity), $\alpha$-carotene, violaxanthin, antheraxanthin, zeaxanthin, and neoxanthin are detected in leaf extract by high-performance liquid chromatography (HPLC) and open column chromatography $[32,43,44]$.

Rocket known to contain significant concentrations of phenolics. Kaempferol as aglycone and glycosides is present in a higher percentage in eatable parts of rocket $[6,31,45]$.

Kaempferol-3 glucoside (astragalin); kaempferol-3,diglucoside -7glucoside; kaempferol-3,4-diglucoside,; kaempferol 3-0-(2"-0-malonyl- $\beta$ D-glucopyranoside)-4'-O- $\beta$-D glucopyranoside; kaempferol 3, 4'-di-Oglucopyranoside, 3-OMichael glucopyranoside, 4'-0-glucopyranoside; quercetin-3,4-diglucoside-3- (6-sinapoyl-glucoside); quercetin-3,3,4triglucoside; quercetin-3-(2-sinapoylglucoside)-3-(6-sinapoylglucoside)4-glucoside; quercetin-3- $\beta$-D-glucoside; rutin; quercetin-3,4 -diglucoside-3 -(6-caffeoyl-glucoside); isorhamnetin-3-glucoside; isorhamnetin-3,4-diglucoside; rhamnocitrin 3-0-(2'-O-methylmalonyl$\beta$-Dglucopyranoside)-4'-O- $\beta$-D-glucopyra-noside, rhamnocitrin 3- O-glucopyranoside, 4'-O-glucopyranoside in rocket leaves juice and aqueous ethanolic extract of fresh leaves by ultrahigh performance LC with high-resolution quadrupole time of flight mass spectral, by LC-MS and other phytochemical investigation methods [44-48]. Kaempferol, myricetin, quercetin, and rhamnocitrin (flavonol aglycon) are also identified in rocket leaves $[46,48,49]$.

Ferulic acid, coumaric acid, vanillin, resorcinol, and catechol are detected in leaf extract by HPLC, and gallic acid was detected in aqueous leaf extract by high-performance thin-layer chromatography. Ellagic, tannic, and gallic acid; quercetin kaempferol; rhamnetin, quercetin triglucoside; rutin, monosynapoyl triglucoside; and kaempferol-3-0-galactoside were the phenolics detected in E. Sativa seed extract. Resorcinol and catechol, benzoic acid, ellagic acid, quercetin, and rutin are detected in flower extract by HPLC $[6,35,44,45,50,51]$. In rocket adult roots, the flavonoid level was very low and therefore not identified.

E. sativa flowers had a very complex anthocyanin (phenolic compounds) profile which was not completely described by LC-MS [52]. The chemical structure of the main flavonoids in E. sativa is shown in Fig. 1.

Glucosinolates as $\beta$-thioglucoside, $\mathrm{N}$-hydrosulfates in the presence of myrosinase, are hydrolyzed forming isothiocyanates, nitriles, thiocyanates and other hydrolytic products depend on $\mathrm{pH}$ and other factors.

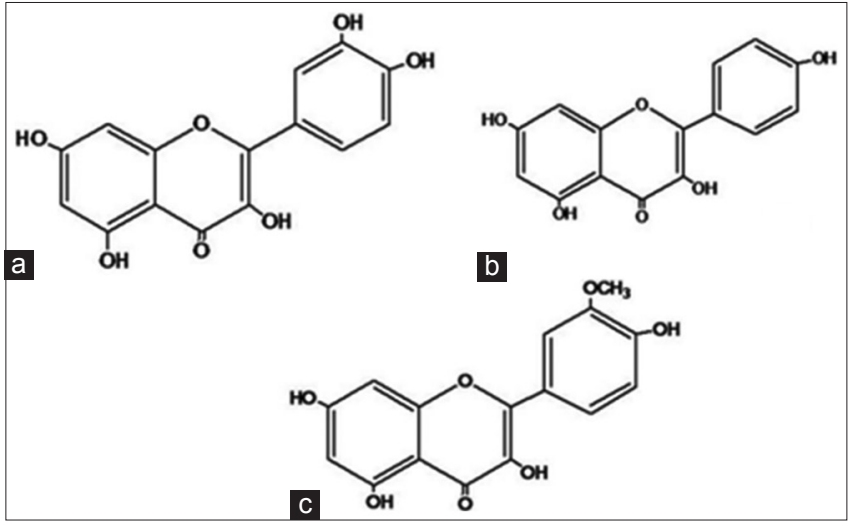

Fig. 1: Main flavonoids in Eruca sativa. (a) quercetin, (b) kaempferol, (c) isorhamnetin [26]

Diglucothiobeinin, glucoalyssin, dihydrogluconapin, glucoamoracin, glucoibarin,glucolepiidin,gluconasturtiin,glucoputranjivin,glucoraphanin, glucosativin, 4-hydroxyglucobrassicin, glucoerucin, glucosinalbin, progoitrin/epiprogoitrin, glucobrassicin, glucocochlearin, glucojiaputin, glucoerysihienin, glucoiberverin, gluconapin, glucotraeolin, neoglucobrassicin, sinigrin, and 4-methoxyglucobrassicin are glucosinolates identified in leaves by LC-MS and HPLC [10,44,48,52-54].

Glucosinolates methylthiobutylglucosinolate, 4-mercaptobutyl glucosinolate, and 4-methylsulfinylbutylglucosinolate are identified in rocket young leaves and roots. 4-mercaptobutylglucosinolate (glucosativin) is the main glucosinolate in E. sativa leaves and flowers formed through S-demethylation of 4-methylthiobutylglucosinolate (glucoerucin). 4-methylthiobutyl glucosinolate and 4-methylslfinylbutyl glucosinolate are existing in lower concentrations [55-58]. Glucoerucin is the predominant glucosinolates in seeds and roots $[6,53,57]$, and it was isolated from alcoholic seed extract in addition to glucoiberin [34]. In seeds, glucoraphanin exists in low level $[59,60]$. The chemical structures of the main glucosinolates are shown in Figs. 2 and 3.

Rocket is a rich source of minerals and electrolyte. Different minerals had been identified in leaves which include phosphor (P), potassium $(\mathrm{K})$, calcium $(\mathrm{Ca})$, magnesium $(\mathrm{Mg})$, sodium $(\mathrm{Na})$, iron $(\mathrm{Fe})$, copper $(\mathrm{Cu})$, manganese (Mn), and zinc (Z) $[27,61,62]$. In leaves, $\mathrm{Mg}, \mathrm{Ca}, \mathrm{Fe}$, and $\mathrm{K}$ are the prevalent minerals, while in seeds, the most abundant minerals are $\mathrm{Ca}, \mathrm{Na}, \mathrm{P}$, and chromium (Cr) [6].

\section{PHARMACOLOGICAL ACTIVITIES OF E. SATIVA}

\section{Antiulcer effect}

Antiulcer effect of E. sativa is known in traditional medicine. Helicobacter pylori which are involved in the pathogenesis of ulcer have a high urease activity, and urease enzyme is essential to $H$. pylori metabolism and required for its colonization in gastric mucosa. E. sativa extract produces a marked reduction of urease activity and thus provides scientific confirmation for its use as antiulcer agent [63].

In experimentally induced gastric lesions, rocket extract has cytoprotective, anti-secretory, and anti-ulcer actions. The anti-ulcer activity may be mediated through an increase in prostaglandin, mucous synthesis, and-or antioxidant activity by inhibiting lipid peroxidation.

Phytochemicals reported in rocket leaves such as flavonoids, sterols, and/or triterpenes are well known for their antioxidant actions, to which anti-ulcer mechanisms may be attributed $[64,65]$.

\section{Antioxidant effect}

Lipid autoxidation is initiated by a chain of lipophilic radicals. In vivo hydrogen peroxide $\left(\mathrm{H}_{2} \mathrm{O}_{2}\right)$ is generated by several oxidase enzymes. $\mathrm{H}_{2} \mathrm{O}_{2}$ through hydroxyl free radical serves as a messenger molecule in the inflammatory mediators' synthesis and activation; these mediators 


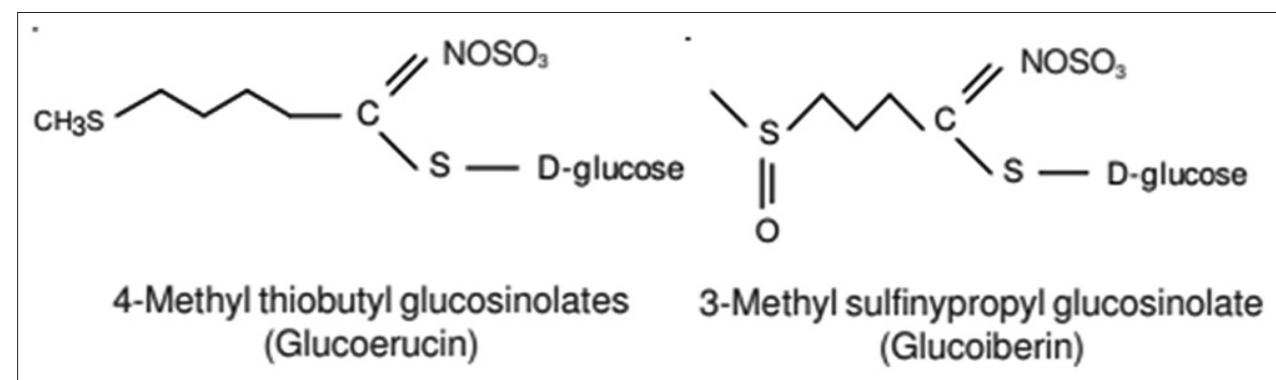

Fig. 2: Chemical structures of glucoerucin and glucoiberin present in Eruca sativa [44]

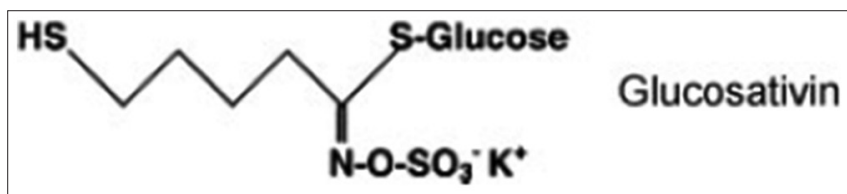

Fig. 3: Chemical structures of glucosativin present in Eruca sativa [44]

are involved in tissue damage and pathogenesis of various diseases such as diabetes [66].

E. sativa flower extract is a powerful antioxidant. 1, 1-diphenyl-2picrylhydrazyl free radical scavenging test and $\beta$-carotene bleaching test were used to estimate the antioxidant effect of flower extract [67]. The concentration of phenolics in leaves is 6 times more than that of rocket stems; kaempferol 3,4-di-0-glucoside, kaempferol 3-glucosyl, quercetin 3-glucosyl, and isorhamnetin 3-glucosyl are the main phenolics in rocket leaves and proved to be a powerful antioxidant [68]. Seed extract contains significant levels of phenolics, these phenolics are considered as natural antioxidant through free radical scavenging or quenching effect. Furthermore, rocket seeds contain significant levels of glucosinolates, especially glucoerucin, which demonstrates the antioxidant effects through phase II enzymes induction, by scavenging hydrogen peroxide and alkyl hydroperoxides gathered in cells and peripheral blood and by serving as a precursor of sulforaphane, a powerful inducer of detoxifying enzymes [69]. The activity of natural antioxidants is less than that of synthetic antioxidant [66].

\section{Antibacterial effect}

E. sativa seed extract has a potent antimicrobial activity, considering it as a promising antibacterial agent against resistant Gram-negative (G-ve) and Gram-positive (G+ve) bacteria [70] which confirm its use as a remedy in traditional medicine for the management of urinary, skin infections, fever, and diarrhea. The bioactive compounds, erucic acid, and isothiocyanates are responsible for antibacterial effect [7]. Isothiocyanates are intermediates formed when glucosinolates are released and hydrolyzed by the action of myrosinase. Allyl isothiocyanates have been shown to display antibacterial action against Bacillus cereus IFO-13494, Pseudomonas aeruginosa IFO-13275, B. subtilis IFO-13722, Escherichia coli JCM-1649, and Staphylococcus aureus IFO-12732, Vibrio parahaemolyticus IFO-12711 E. coli 0157:H7, H. pylori, and others [71]. It was found that extracts of E. sativa seeds had a remarkable antibacterial action against $S$. aureus and B. cereus [72]. Eruca seed oil also exerts antibacterial and antifungal effects [73].

\section{Effect on fertility}

Since Roman times, rocket was recognized as a powerful aphrodisiac remedy [74]. Ethanolic extract of E. sativa was reported to have an androgenic action or induce testicular steroids production which stimulates the preputial gland, as well it enhances spermatogenesis in the male mice testis [75]. A considerable rise in testosterone hormone level and sperm activity was attributable to the extract of rocket leaves; furthermore, a significant reduction in sperm death and abnormalities was observed. The existence of saponins and alkaloids in rocket extract produce a significant enhancement in sperm activity. On comparison to the control group, histological sections of seminiferous tubules showed a significant increase in diameter of these tubules, spermatids, and Leyding cells and reduction in interstitial space was observed after five weeks of using with E. sativa extract. This increment might be attributed to the ability of rocket extract to activate testes growth and enhancement of spermatozoa proliferation, maturation, and differentiation as compared with the control group [76]. Rocket seed oil showed a protective effect against nicotine-induced testicular damage by reversing (almost entirely) all morphometric and histological modifications in testis caused by nicotine [77].

Both Eruca leaves and seeds have aphrodisiac effect. In seeds, the aphrodisiac effect may be attributed to desulfoglucosinolates, erucic acid, and an essential oil that is rich in isothiocyanates or to a combination of these phytochemicals [78].

Mona et al. in their study revealed that small doses of seeds oil stimulate spermatogenesis, while large doses suppress spermatogenesis possibly due to erucic acid high content [79].

\section{Hepatoprotective effect}

Ethanolic and aqueous rocket leaf extracts demonstrate hepatoprotective effect against carbon tetrachloride, phosphoric acid, and paracetamol-induced liver toxicity $[11,20,25]$. The liver toxicity is due to free radicals that have the ability either for proteins binding or abstracting a hydrogen atom from unsaturated molecules of lipid, and hence, accelerating or fastening lipid peroxidation and toxic effect. El-Nattat and ElKady said that the activities of alanine aminotransferase and aspartate aminotransferase are promoted due to rocket administration in male rabbits, and this probably attributed to the high sulfur content in rocket that expels body wastes. E. sativa leaves and seeds significantly restore non-protein sulfhydryl level in liver tissue, supporting or assisting the liver and immune function. The possible hepatoprotective activity of ethanolic rocket extract may be due to the suppression of the cytochrome P450 oxygenase enzyme system and glucoerucin (the major glucosinolate in rocket) which has indirect and direct antioxidant actions in addition to hydroperoxides and $\mathrm{H}_{2} \mathrm{O}_{2}$ decomposition properties $[11,80]$.

\section{Hyperlipidemic effect}

The major cause of atherosclerosiswhich is highly correlated to ischemic heart disease is hypercholesterolemia and hypertriglyceridemia [81]. E. sativa leaf extract possesses antihyperlipidemic and antihypercholesterolemic effects [82]. The antihyperlipidemic action of rocket leaf extract perhaps due to Vitamin C activation of the 7alpha-hydroxylase enzyme. E. sativa leaves conations Vitamin C, which promotes plasma cholesterol conversion into bile acid, as a result subsequent decrease in serum cholesterol levels, additionally the capacity of the Vitamin C to prevent the oxidation of high-density lipoprotein [23]. The rocket oil hypocholesterolemic effect perhaps due to the phytosterols; $\beta$-sitosterol, campasterol and beta-amyrine. (these sterols decrease cholesterol concentration by preventing its absorption and inactivation of the hepatic cholesterol esterase) or due to high ratio of unsaturated fatty acids which decrease lipoproteins 
production. Phytosterols reduced the dietary and biliary cholesterol conjugation into micelles, and this depresses cholesterol absorption. Synthesis of cholesterol and low-density lipoprotein (LDL) receptors activity is increased, which eventually leads to reduced serum LDLcholesterol concentration. The rocket oil hypocholesterolemic effect is better than that of olive oil $[82,83]$. Hence, rocket oil decreases the total cholesterol, total lipid, and LDL concentration and can be considered as worthy source for omega fatty acids and might be consumed as a healthy oil to minimize saturated oil consumption. Saturated oils and fats are the reasons for the development of several chronic illnesses [84].

\section{Antihypertensive effect}

Rocket had been utilized as a remedy in traditional medicine for managing the cardiovascular complaints, particularly hypertension [85-87]. Oral and intravenous administration methanolic extract of rocket aerial parts and its fractions (especially aqueous fraction) demonstrates hypotensive effect in normotensive and hypertensive rats (hypertension is induced by high salt diet). The antihypertensive effect is the net result of vasodilatory and cardiotonic effects. Vasodilatory mediators, as nitric oxide and certain muscarinic receptors existing on vascular endothelial cells, are implicated in vasodilation. Activation of these receptors ultimately leads to nitric oxide production. Rocket extract also has a direct influence on vascular smooth muscle in rat. Crude extract and, especially, ethyl acetate fraction are loaded with flavonoids and phenols; previous studies revealed that the flavonoids and phenols have anticholinesterase and cardioprotective effects and may be implicated in hypotensive effect. Erucin (also major component of rocket) is produced from sulforaphane metabolism. Sulforaphane is known with potential hypotensive effect, so the antihypertensive effect is possibly due to quercetin, erucin, and other rocket constituents [88].

\section{Antidiabetic effect}

Rocket seeds and leaves ameliorate hyperglycemia and produce antidiabetic effect [89-91]. E. sativa seed oil has powerful antihyperglycemic and antihyperlipidemic actions in streptozotocin (STZ)-induced diabetic rats. High glucose concentration yields reactive oxygen species (ROS) due to autoxidation, metabolism of glucose, and the development of advanced glycosylation end products. ROS activates lipid peroxidation that causes devastation and injury to the cell membrane; lipid peroxidation is one of the distinctive features of chronic diabetes.

The protective effects of rocket seeds oil against hyperglycemia and hyperlipidemia probably as a result of their ability to modulate the pancreatic islets architecture, antioxidant activity (through free radical scavenging activity), increasing (glutathione and superoxide dismutase concentration) and insulin secretory response $[92,93]$.

E. sativa extract shows suppressing effect on carbohydrate metabolism through inhibition of carbohydrate-hydrolyzing enzymes, $\alpha$-amylase, $\alpha$-glucosidase, and $\beta$-galactosidase in dose-dependent manner. Aqueous extract exhibited less inhibitory effect than ethanolic extract on carbohydrate metabolism [91].

Oral administration of rocket leaves extract in STZ-induced diabetic rats greatly retrieves the abnormal parameters in experimental animals. Hence, E. sativa may be valuable for patients who suffer from diabetes [94].

\section{Antifungal effect}

Rocket leaf oil that extracted by steam distillation has significant antifungal effect assessed by well-diffusion method. The extracted oil has a high rate of inhibition (60-67\%) against Dreschlera halodes, Cola clavata, Rhizopus oryzae, and Aspergillus nidulans. While the oil moderately suppress Alternaria kiliense (49\%), Alternaria alternata $(38 \%)$ and exhibited minimum inhibition against $F$. oxysporum with (13\%) [14]. Powdered seeds of E. sativa demonstrate antifungal effect. Crude aqueous seeds exhibited strong powerful antifungal effect against the fungus Spadicoides stoveri and Paecilomyces variotii while insignificant inhibition against other fungal strains [95].

\section{Anti-inflammatory and antiedema effect}

Rocket seeds are used by traditional herbalists for the management of rheumatoid arthritis. Abodola et al. designed a study to assess the antiinflammatory effect of Eruca seeds, and his study revealed that ethanolic seed extract demonstrates a dose-dependent sustained anti-edema action superior to indomethacin. The anti-inflammatory effect of seeds possibly mediated through flavonoids as quercetin and isorhamnetin, also to 4-methylthiobutyl isothiocyanate (main isothiocyanates in seeds). 4-methylthiobutyl isothiocyanate inhibits the expression of pro-inflammatory genes, tumor necrosis factor-alpha, and some other interleukins (ILs). Non-steroidal anti-inflammatory drugs are known for their deleterious effect on gastric mucosa, while E. sativa extract has gastroprotective effect. Large doses of rocket may cause anaphylaxis and immunosuppression [96].

\section{Nephroprotective effect}

Rocket is generally used in traditional medicine as a remedy for renal disease. Elgazar and his colleague proved that E. sativa induced diuresis and has nephroprotective effect against gentamicin-induced nephrotoxicity in rats $[97,98]$.

The rocket alsoholic seed extract has nephroprotective action in mercuric chloride $\left(\mathrm{HgCl}_{2}\right)$-induced nephrotoxicity. This protective effect due to the ability of seed extracts of E. sativa for rising or maintaining the antioxidant molecules and antioxidant enzymes levels in the kidney and through the protective effect to kidney, thereby protect the tissues against oxidative damage. Flavonoids and glucoerucin present in rocket seeds extract may be involved in nephroprotective activity [99].

Hussien proved in his study that the aqueous extract of E. sativa successfully prevents the occurrence of nephrocalcinosis in rabbits through suppression calcium oxalate crystal formation and deposition in renal tissues. Prevention of nephrocalcinosis of rocket is due to its diuretic effect and alkalization of urine (calcium oxalate crystals deposing is enhanced in acidic urine). Furthermore, E. sativa has a large amount of magnesium, and thus, it may lessen free oxalate in intestine and urine, reducing its availability for binding to $\mathrm{Ca}$ ion in renal tubules, and thus, calcium oxalate crystal formation is suppressed [100-102].

\section{Antiplatelet effect}

Platelets activation has a role player in the development of acute thrombus and cardiovascular diseases. Hydroalcoholic extract of rocket leaves exhibited antiplatelet effect (both in vivo and in vitro); as it prevents thrombus formation without significant risk of bleeding. E. sativa extract restrains thromboxane B2, tissue growth factor (1ß), and IL-1 $\beta$ which are platelet inflammatory mediators, and these mediators participate in the development of atherosclerotic lesion and arterial thrombogenesis. Human platelet CCL5 levels which are induced by adenosine diphosphate also inhibited by $E$. sativa extract but lo lesser extent. These effects ultimately prevent thrombus development. E. sativa Mill antiplatelet activity could be explained by the existence of kaempferol, quercetin, and isorhamnetin. Kaempferol derivatives are the major phenolics in rocket leaves [103].

\section{Other effects}

A mixture of milled seeds of E. sativa and cream was applied on the face for its antiacne effect [104]. Lotion of E. sativa promotes hair regrowth and reverse greasy scalp [105]. Orally administered mixture of seeds oil and sugar is used for the treatment of dysentery [106].

\section{STUDIES INVOLVE DEVELOPMENT OF PHARMACEUTICAL PREPARATION CONTAINING E. SATIVA EXTRACT}

Shatalebi et al. studied the development of an oil/water (o/w) hair wax formulas for hair growth containing ethanolic extract $E$. sativa seed oil, with the aid of thickening agents in different concentrations. 
The resultant formulations were evaluated and compared to brand marketed product. Best results were observed with formula containing $10 \%$ ethanolic extract of propolis and $10 \%$ E. sativa seed oil. This formula increased the hair length, the newly grown hairs weight, and improved percentage phase of hair follicles [107].

Sanad et al. formulated and evaluated enriched garlic and Eruca oils stable cream with antibacterial activity. Different formulations were prepared using different concentrations of two surface active agents. Cream prepared with $2 \%$ surfactant mixture showed well-designed formulation and best antimicrobial activity [108].

Taha et al. formulated a new herbal antifungal hair cream containing Eruca and garlic oils, active on pathogenic fungi (Malassezia furfur, Microsporum canis Bodin, and Trichophyton mentagiophytes) using different ratios of non-ionic surfactant. Highest permeation rate of alliin in the presence of Eruca oil which is necessary for antifungal activity was obtained with formula of 4\% concentration of Span and Brij [109].

\section{CONCLUSION}

Plants and herbal extracts constitute a vital position in modern medicine; E. sativa is an important nutraceutical that has diverse phytochemicals. Although the plant was excessively studied and many compounds have been isolated, further studies are required to support the traditional uses of plant. Scientific research should be employed to isolate, elucidate, and specify the chemical structure of each compound responsible for specific pharmacological action. In addition, more pharmaceutical studies should be employed to formulate more dosage forms containing the active constituents of E. sativa due to broad pharmacological activity of them.

\section{ACNOWLEDGMENT}

The authors are inclined to state their gratefulness to Baghdad University (www.uobaghdad.edu.iq), College of pharmacy and Al-Mustansiriyah University (www.uomustansiriyh.edu.iq), and College of pharmacy, Baghdad, Iraq, for their incessant support to scientific output.

\section{AUTHORS' CONTRIBUTION}

We declare that this work was done by the authors named in this article and all liabilities pertaining to claims relating to the content of this article will be borne by the authors. Both Dr. Noor S Jaafar and Dr. Iman S Jaafar assembled and studied the data. Dr. Iman S Jaafar proof read the whole manuscript and recommended the required changes and Dr. Noor S Jaafar assist in designing manuscript.

\section{CONFLICTS OF INTEREST}

The authors declare that there are no conflicts of interest regarding the publication of this paper.

\section{REFERENCES}

1. Al-Shimmary BA. Study the sub acute effect of Eruca sativa leaves extract on hematological parameters of male rats. Kufa J Vet Sci 2017;8:232-7.

2. Al-Qudah MM. Effects of Eruca sativa leaves extracts on testes, fertility potential and testosterone concentration in male rats. Ann Res Rev Bio 2017;16:1-7.

3. El Nagar MM, Mekawi EM. Comparison of different genotypes of rocket (Eruca sativa) in terms of chemical. Middle East J Agric 2014;3:1074-82.

4. Dolezalova V, Duchoslav M, Dusek K. Biology and yield of rocket (Eruca sativa Mill.) under field conditions of the Czech Republic (Central Europe). Not Bot Horti Agrobo 2013;41:530-7.

5. Bansal P, Medhe S, Ganesh N, Srivastava MM. Antimelanoma potential of Eruca sativa seed oil and its bioactive principles. Indian J Pharm Sci 2015;77:208-17.

6. Cavaiuolo M, Ferrante A. Nitrates and glucosinolates as strong determinants of the nutritional quality in rocket leafy salads. Nutrients 2014;6:1519-38.
7. Khoobchandani M, Ojeswi BK, Ganesh N, Srivastava MM, Gabbanini S, Matera R, et al. Antimicrobial properties and analytical profile of traditional Eruca sativa seed oil: Comparison with various aerial and root plant extracts. Food Chem 2010;120:217-24.

8. Somos AS, Koukounaras A. Quality and postharvest physiology of rocket leaveshemical. Fresh Produce 2007;1:59-65.

9. Kishore L, Kaur N, Kajal A, Singh R. Extraction, characterization and evaluation of Eruca sativa against Streptozotocin-induced diabetic nephropathy in rat. Bangladesh J Pharm 2017;12:216-27.

10. Bouacida S, Koubaier H, Snoussi A, Fauconnier ML, Bouzouita N. Glucosinolate profiles by HPLC-DAD, phenolic compositions and antioxidant activity of Eruca vesicaria longirostris: Impact of plant part and origin. Med J Chem 2016;5:528-39.

11. Alqasoumi S. Carbon tetrachloride-induced hepatotoxicity: Protective effect of 'rocket' Eruca sativa L. in rats. Am J Chin Med 2010;38:75-88.

12. Ansari MN. Influence of dietary rocket leaves on diuresis and urinary electrolytes excretion in high fat diet-induced obese rats. BEPLS 2015;4:9-13.

13. El Nagar MM, Mekawi EM. Comparison of different genotypes of rocket (Eruca sativa) in terms of chemical compounds extracted from seeds and in the callus induced from tissue culture. Int J Appl Res Rev 2014;3:1074-82.

14. Ali A, Bashir U, Haider MS. Bio - control effect of Eruca sativa Mill. oil against the hazardous food borne pathogens. Pak J Pat 2014;26:181-5.

15. Farooq Z, Iqbal Z, Mushtaq S, Muhammad G, Iqbal MZ, Arshad M, et al. Ethnoveterinary practices for the treatment of parasitic diseases in livestock in cholistan desert (Pakistan). J Ethnopharmacol 2008;118:213-9.

16. Gugliandolo A, Giacoppo S, Ficicchia M, Aliquò A, Bramanti P, Mazzon E, et al. Eruca sativa seed extract: A novel natural product able to counteract neuroinflammation. Mol Med Rep 2018;17:6235-44.

17. Shaban N, Abdel-Rahman S, Haggag A, Awad D, Bassiouny A, Talaat I, et al. Combination between taxol-encapsulated liposomes and Eruca sativa seed extract suppresses mammary tumors in female rats induced by 7,12 dimethylbenz $(\alpha)$ anthracene. Asian Pac J Cancer Prev 2016;17:117-23.

18. Baeshen AA. Use of pseudomonas aeruginosa as fertilizer in Eruca sativa. IJCAMS 2016;5:301-12.

19. Mahdy SS. The antigenotoxicity of Eruca sativa Mill extract on bone marrow cells of male albino mice treated with vincristine. IHJPAS 2012;25:26-32.

20. EL Sadek MF. Chemical constituents of Eruca sativa and treatment activity against paracetamol inducing hepatic injury in experimental rats. J Nutr Health 2014;9:73-84.

21. Marwat SK, Rehman F, Khan AA. Phytochemistry and pharmacological values of rocket (Eruca sativa Miller). Int J Health 2016;6:1-7.

22. Arora R, Singh B, Vig AP, Arora S. Conventional and modified hydrodistillation method for the extraction of glucosinolate hydrolytic products: A comparative account. Springerplus 2016;5:479.

23. Bell L, Methven L, Signore A, Concha MJ, Wagstaff C. Analysis of seven salad rocket (Eruca sativa) accessions: The relationships between sensory attributes and volatile and non-volatile compounds. Food Chem 2017;1:181-91.

24. Uğur A, Süntar I, Aslan S, Orhan IE, Kartal M, Sekeroğlu N, et al. Variations in fatty acid compositions of the seed oil of Eruca sativa Mill. Caused by different sowing periods and nitrogen forms. Pharmacogn Mag 2010;6:305-8.

25. Mashi SK. Effect of Eruca sativa leaves extract on liver enzymes and lipid profile in phosphoric acid induced liver damage in male rabbits. J Entomol Zool Stud 2017;5:1011-5.

26. Kole C. Wild Crop Relatives: Genomic and Breeding Resources: Oilseeds. Berlin Heidelberg: Springer-Verlag; 2011. p. 158.

27. Garg G, Sharma V. Eruca sativa (L.): Botanical description, crop improvement, and medicinal properties. J Herbs Spices Med Plants 2014;20:171-82.

28. Gupta SK. Biology and Breeding of Crucifers. London: CRC Press; 2011. p. 46-7.

29. Jirovetz L, Smith D, Buchbauer G. Aroma compound analysis of Eruca sativa (Brassicaceae) SPME headspace leaf samples using GC, GC-MS. J Agric Food Chem 2002;50:4643-6.

30. Ahmed DI. Role of Eruca sativa, Negella sativa and bee pollen grains in improving liver, kidney and antioxidant status in rats. Int J Biol Pharm All Sci 2015;4:6604-19.

31. Gulfrazi M, Sadiqi A, Tariq H, Imran M, Qureshi R, Zeenat A. Phytochemical analysis and antibacterial activity of Eruca sativa seed. Pak J Bot 2011;43:1351-9.

32. Yadava TP, Friedt DW, Gupta SK. Oil content and fatty acid 
composition of taramira (Eruca sativa L.) genotypes. J Food Sci Technol 2013;35:557-8.

33. Tassi EM, Duarte RM, Amaya-Farfan J. Partial nutrient characterization of arugula (rocket - Eruca sativa L.) and the effect of heat treatment on its lipoxidase activity. Brazil J Food Sci Technol 2018;24:1-7.

34. Tonguc M, Erbas S. Evaluation of fatty acid compositions and some seed characters of common wild plant species of Turkey. Turk J Agric 2012;36:673-9.

35. Nazif NM, Habib A, Tawfik W, Hassan R. Chemical composition and cytotoxic activity of Eruca sativa L. seeds cultivated in Egypt. Asian J Chem 2010;22:2407-16.

36. Hetta MH, Owis AI, Haddad PS, Eid HM. The fatty acid-rich fraction of Eruca sativa (rocket salad) leaf extract exerts antidiabetic effects in cultured skeletal muscle, adipocytes and liver cells. Pharm Biol 2017;55:810-8.

37. Ohta K, Takeshita T, Funabashi M, Oda S. Naturally grown rucola, Eruca sativa, contains more $\alpha$-linolenic acid than conventionally grown rucola. Plant Biotechnol J 2016;33:277-9.

38. Nagaraj G. Oilseeds: Properties, Processing, Products and Procedures. India: New India publishing Agency; 2009. p. 36.

39. El-Fadaly HA, El-Kadi SM, El-Moghazy MM, Soliman AA, El-Haysha MS. Antioxidant activity studies on extracts of Eruca sativa seed meal and oil, detoxification, the role of antioxidants in the resistant microbes. Int J Sci Res Med 2017;6:31-51.

40. Saqqa GA, Alian A, Ismail F, Ramzy S. Chemical composition of rocket, thyme and parsley essential oils and their effect on some fungi and aflatoxin production. J Toxicol Appl Pharm 2018;4:277-82.

41. Miyazawa M, Maehara T, Kurose K. Composition of the essential oil from the leaves of Eruca sativa. Flavor Fragr J 2002;17:187-90.

42. Omri Hichri A, Mosbah H, Majouli K, Besbes Hlila M, Ben Jannet H, Flamini G, et al. Chemical composition and biological activities of Eruca vesicaria Subsp. Longirostris essential oils. Pharm Biol 2016;54:2236-43.

43. Znidarčič D, Ban D, Sircelj H. Carotenoid and chlorophyll composition of commonly consumed leafy vegetables in Mediterranean countries. Food Chem 2011;129:1164-8.

44. Villatoro-Pulido M, Priego-Capote F, Álvarez-Sánchez B, Saha S, Philo M, Obregón-Cano S, et al. An approach to the phytochemical profiling of rocket [Eruca sativa (Mill.) thell]. J Sci Food Agric 2013;93:3809-19.

45. Michael HN, Shafik RE, Rasmy GE. Studies on the chemical constituents of fresh leaf of Eruca sativa extract and its biological activity as anticancer agent in vitro. J Med Plants Res 2011;5:1184-91.

46. Corleto KA, Singh J, Jayaprakasha GK, Patil BS. Storage stability of dietary nitrate and phenolic compounds in beetroot (Beta vulgaris) and arugula (Eruca sativa) juices. J Food Sci 2018;83:1237-48.

47. Kim B, Choi YE, Kim HS. Eruca sativa and its flavonoid components, quercetin and isorhamnetin, improve skin barrier function by activation of peroxisome proliferator-activated receptor (PPAR)- $\alpha$ and suppression of inflammatory cytokines. Phytother Res 2014;28:1359-66.

48. Cartea ME, Francisco M, Soengas P, Velasco P. Phenolic compounds in brassica vegetables. Molecules 2010;16:251-80.

49. Bell L, Wagstaff C. Glucosinolates, myrosinase hydrolysis products, and flavonols found in rocket (Eruca sativa and Diplotaxis tenuifolia). J Agric Food Chem 2014;62:4481-92.

50. Abdul-Jalil TZ. Phytochemicals screening by GC/MS and determination of some flavonol in cultivated Iraqi Eruca sativa dried leaves extract and its biological activity as antioxidant. Int J Pharm Pharm Res 2016;8;1722-30.

51. Sadiq A, Hayat MQ, Mall SM. Qualitative and quantitative determination of secondary metabolites and antioxidant potential of Eruca sativa. Nat Prod Chem Res 2014;2:1-7.

52. Sajeeth CI, Manna PK, Manavalan R, Jolly C. Quantitative estimation of gallic acid, rutin and quercetin in certain herbal plants by HPTLC method. Der Chem Sin 2010;1:80-5.

53. Di Gioia F, Avato P, Serio F, Argentieri MP. Glucosinolate profile of Eruca sativa, Diplotaxis tenuifolia and Diplotaxis erucoides grown in soil and soilless systems. J Food Compost Anal 2018;69:197-204.

54. Chun J, Arasu MV, Lim Y, Kim S. Variation of major glucosinolates in different varieties and lines of rocket salad. Hort. Environ Biotechnol 2013;54:206-13

55. Bell L, OrunaConcha MJ, Wagstaff C. Identification and quantification of glucosinolate and flavonol compounds in rocket salad (Eruca sativa, Eruca vesicaria and Diplotaxis tenuifolia) by LCMS: Highlighting the potential for improving nutritional value of rocket crops. Food Chem 2015;172:852-61.

56. Bennett RN, Rosa EA, Mellon FA, Kroon PA. Ontogenic profiling of glucosinolates, flavonoids, and other secondary metabolites in Eruca sativa (salad rocket), Diplotaxis erucoides (wall rocket), Diplotaxis tenuifolia (wild rocket), and Bunias orientalis (Turkish rocket). J Agric Food Chem 2015;54:4005-15.

57. Grubben GJ, Denton OA. Plant Resources of Tropical Africa 2 Vegetables. Netherlands: PROTA Foundation, Backhuys Publishers; 2004. p. 295.

58. Kim S, Ishii G. Glucosinolate profiles in the seeds, leaves and roots of rocket salad (Eruca sativa Mill.) and anti-oxidative activities of intact plant powder and purified 4-methoxyglucobrassicin. J Soil Sci Plant Nutr 2006;52:394-400.

59. Fechner J, Kaufmann M, Herz C, Eisenschmidt D, Lamy E, Kroh LW, et al. The major glucosinolate hydrolysis product in rocket (Eruca sativa L.), sativin, is 1,3-thiazepane-2-thione: Elucidation of structure, bioactivity, and stability compared to other rocket isothiocyanates. Food Chem 2018;261:57-65.

60. Bennett RN, Carvalho R, Mellon FA, Eagles J, Rosa EA. Identification and quantification of glucosinolates in sprouts derived from seeds of wild Eruca sativa L. (salad rocket) and Diplotaxis tenuifolia L. (wild rocket) from diverse geographical locations. J Agric Food Chem 2007;55:67-74.

61. Neugart S, Baldermann S, Hanschen FS, Klopsch R, Wiesner-Reinhold $\mathrm{M}$, Schreiner M. The intrinsic quality of brassicaceous vegetables: How secondary plant metabolites are affected by genetic, environmental, and agronomic factors. Sci Hort 2018;233:460-78.

62. Barlas NT, Irget ME, Tepecik MM. Mineral content of the rocket plant (Eruca sativa). AJB 2011;10:14080-82.

63. Guenane H, Gherib A, Bakchiche B, Carbonell-Barrachina AA. Antioxidant capacity, mineral content and essential oil composition from select algerian medicinal plants. St. Cerc. St. CICBIA 2017; 18:275-89.

64. Khan H, Khan MA. Antiulcer effect of extract/Fractions of Eruca sativa: Attenuation of urease activity. J Evid Based Complementary Altern Med 2014;19:176-80

65. Thiab A, Hussein S, Hamad MN. Possible gastric protective and therapeutic effect of Eruca sativa laxative extract against ulcer induced by ethanol in rats. Int $\mathrm{J}$ Pharm Clin 2016;3:1-6.

66. Alqasoumi S, Al-Sohaibani M, AlHowiriny $\mathrm{T}$, AlYahya M, Rafatullah S. Rocket "Eruca sativa": A salad herb with potential gastric antiulcer activity. World J Gastroenterol 2009;15:1958-65.

67. Kishore L, Kaur N, Singh R. Evaluation of antioxidant activity and total phenolic content of Eruca sativa L. Seeds. Int J Toxicol Pharm Res 2016;8:146-51.

68. Koubaa M, Driss D, Bouaziz F, Ghorbe RE, Chaabouni SE. Antioxidant and antimicrobial activities of solvent extract obtained from rocket (Eruca sativa L.) flowers. Free Rad Antiox 2015;5:29-34.

69. Maia ML, Correia-Sá L, Coelho A, Barroso MF, Domingues VF, Delerue-Matos C, et al. Eruca sativa: Benefits as antioxidants source versus risks of already banned pesticides. J Environ Sci Health B 2015;50:338-45.

70. Barillari J, Canistro D, Paolini M, Ferroni F, Pedulli GF, Iori R, et al. Direct antioxidant activity of purified glucoerucin, the dietary secondary metabolite contained in rocket (Eruca sativa mill.) seeds and sprouts. J Agric Food Chem 2005;53:2475-82.

71. Rizwana H, Mona S, Alwhibi FK, Soliman DA. Chemical composition and antimicrobial activity of Eruca sativa seeds against pathogenic bacteria and fungi. J Appl Pharm Sci 2016;26:1859-77.

72. Doulgeraki AI, Efthimiou G, Paramithiotis S, Pappas KM, Typas MA, Nychas GJ, et al. Effect of rocket (Eruca sativa) extract on MRSA growth and proteome: Metabolic adjustments in plant-based media. Front Microbiol 2017;8:782

73. Malik SN. Antibacterial activity of olive (Olea europaea) leaves and arugula (Eruca sativa) seeds extract. Int $\mathrm{J}$ Pharm Pharm Res 2015;7:307-10

74. Razooqi RH, Shkeer HK, Alwan YO, Hayder MI. Effect of Eruca sativa oil on broilers preformance and some blood traits. Int J Sci Nat 2014;4:479-82.

75. Ansari MN, Ganaie MA. Ameliorative effect of rocket leaves on fertility in streptozotocin-induced diabetic rats. Int Res 2014;3:89-97.

76. Hadi MA, Almamoori AM, Alaa TS, Hameedi EH. Oxidative response associated with treatment of male albino rats with Eruca sativa Mill leaves extract and correlations with complete blood picture. Int $\mathrm{J}$ Pharm Sci Res 2017;9:2278-85.

77. Hussein ZF. Study the effect of Eruca sativa leaves extract on male fertility in albino mice. J Univ Nat Sci 2013;16:143-6.

78. Abd El-Aziz GS, El-Fark MO, Hamdy RM. Protective effect of Eruca sativa seed oil against oral nicotine induced testicular damage in rats. 
Tissue Cell 2016;48:340-8.

79. Alhowiriny TA, Al-Rehaily AJ, El Tahir KE, Al-Taweel AM, Perveen S. Molecular mechanisms that underlie the sexual stimulant actions of ginger (Zingiber officinale Rosocoe) and garden rocket (Eruca sativa L.). J Med Pharm Res 2013;7:2370-9.

80. Salem MA, Moustafa NA. Histological and quantitative study of the effect of Eruca sativa seed oil on the testis of albino rat. Egypt J Hosp Med 2001;2:148-62.

81. Hussein J, Salah A, Oraby F, Nour El-Deen A, El-Khayat Z. Antihepatotoxic effect of Eruca sativa extracts on alcohol induced liver injury in rats. J Med Sci 2010;6:381-9.

82. Shatta GF. A review article on hyperlipidemia: Types, treatments and new drug targets. BPJ 2014;7:399-409.

83. Uzun M, Kaya A. Ethnobotanical research of medicinal plants in Mihalgazi (Eskișehir, Turkey). Pharm Biol 2016;54:2922-32.

84. El-Gengaihi SE, Salem A, Bashandi SA, Ibrahim NA, Abd el-Hamid SR. Hypolipidemic effect of some vegetable oils in rats' food. Agric Environ 2004;2:88-93.

85. Seham SK, Magda SM, Madiha MA. Effect of some plant oils and garlic on lipids of rats fed on high cholesterol diet. Int Food Res J 2015;22:1307-14

86. Shah AJ, Salma U, Khan T, Khan S, Qayyum R, Qamar H. Antihypertensive effects and potential vascular mechanisms of the extract and fractions of Eruca sativa and euricin. Clin Exp Pharmacol 2016;6:59-65.

87. Amjad MS. Ethnobotanical profiling and floristic diversity of Bana valley, Kotli (Azad Jammu and Kashmir). Pak Appl Pharm J Pharm Tech 2015;5:292-9.

88. Ali-Shtayeh MS, Jamous RM, Jamous RM, Salameh NM. Complementary and alternative medicine (CAM) use among hypertensive patients in Palestine. Complement Ther Clin Pract 2013;19:256-63.

89. Salma U, Khan T, Shah AJ. Antihypertensive effect of the methanolic extract from Eruca sativa Mill. (Brassicaceae) in rats: Muscarinic receptor-linked vasorelaxant and cardiotonic effects. J Ethnopharmacol 2018;224:409-20.

90. Melchini A, Traka MH. Biological profile of erucin: A new promising anticancer agent from cruciferous vegetables. Toxins (Basel) 2010;2:593-612.

91. Peter SJ, Sabina EP. Global current trends in natural product for diabetes managements Int J Pharm Pharm Scii 2016;8:21-8.

92. Hetta MH, Aly HF, Arafa A. Inhibitory effect of Eruca sativa Mill. On carbohydrate metabolizing enzymes. Int J Pharm Sci Rev Res 2014;26:205-8.

93. Ahmed OM, Abdel-Reheim ES, Ashour MB, Fahim HI, Mohamed HH. Efficacies of Eruca sativa and Raphanus sativus seeds' oils in streptozotocin induced diabetic rats. Int $\mathrm{J}$ Clin Endocrinol Metab
2016;2:34-43.

94. El-Missiry MA, El Gindy AM. Amelioration of alloxan induced diabetes mellitus and oxidative stress in rats by oil of Eruca sativa seeds. Ann Nutr Metab 2000;44:97-100.

95. Ansari MN. Ameliorative effect of Eruca sativa extracts on glucose and urinary volume in streptozoticine - induced diabetic rats. Int J Biol Pharm All Sci 2014;3:1092-100.

96. Rani I, Akhund S, Suhail V, Abro H. Antimicrobial potential of seed extract of Eruca sativa. Pak J Bot 2010;42:2949-53.

97. Abodola MA, Lutfi MF, Bakhiet AO, Mohamed AH. The anti-edema effect of Eruca sativa seeds. Science 2015;5:1340-4.

98. Elgazar AF, AboRaya AO. Nephroprotective and diuretic effect of three medicinal herbs against gentamicin-induced nephrotoxicity in male rats. PJN 2013;12:715-22.

99. Shalaby MA, Hammouda AA. Nephroprotective diuretic and antioxidant effects of some medicinal herbs in gentamicin-nephrotoxic rats. J Intercult Ethnopharmacol 2014;3:1-8.

100. Sarwar Alam M, Kaur G, Jabbar Z, Javed K, Athar M. Eruca sativa seeds possess antioxidant activity and exert a protective effect on mercuric chloride induced renal toxicity. Food Chem Toxicol 2007;45:910-20.

101. Hussein UA. Role of Eruca sativa in prevention of induced nephrocalcinosis in rabbits. Kerbala J Pharm Sci 2018;14:65-73.

102. Aggarwal D, Sharma M, Singla SK. The role of natural antioxidants as potential therapeutic agent in nephrolithiasis. Asian J Pharm Clin Res 2013;6:48-53

103. Alarcón M, Fuentes M, Carrasco G, Palomo I. A novel role of Eruca sativa mill. (Rocket) extract: Antiplatelet (NF- $\kappa$ B Inhibition) and antithrombotic activities. Nutrients 2014;6:5839-52.

104. Ramzan I, Phytotherapies: Efficacy, Safety, and Regulation United State of America. New Jersey: John Wiley and Sons, Inc. Hoboken; 2015. p. 172.

105. Dris R, Jain SM, Khan IA. Environment and Crop Production. New York: CRC Press; 2002. p. 68

106. Abbasi AM, Khan SM, Ahmad M, Khan MA, Quave CL, Andrea A. Botanical ethnoveterinary therapies in three districts of the lesser Himalayas of Pakistan. Ethnobiol Ethnomed 2013;9:1-20.

107. Shatalebi MA, Safaeian L, Baradaran A, Alamdarian M. Preparation and evaluation of a hair wax containing propolis and Eruca sativa seed oil for hair growth. Adv Biomed Res 2016;28:182.

108. Sanad RA, Mabrouk MI. Development and assessment of stable formulations containing two herbal antimicrobials: Allium sativum L. and Eruca sativa miller seed oils. Drug Dev Ind Pharm 2016;42:958-68

109. Taha KF, Elhawary SS, Elefnawy HM, Mabrouk MI, Sanad RA, Elharriry MY. Formulation and assessment of herbal hair cream against dermatophytes. Int J Pharm Pharm Sci 2016;8:167-73. 